\title{
Antioxidant properties of polyphenol-rich cocoa products industrially processed
}

\author{
Guillermo Schinella ${ }^{\mathrm{a}}$, Susana Mosca ${ }^{\mathrm{b}}$, Elena Cienfuegos-Jovellanos ${ }^{\mathrm{c}}$, María Ángeles Pasamar ${ }^{\mathrm{c}}$, \\ Begoña Muguerzac ${ }^{c}$, Daniel Ramón ${ }^{\mathrm{d}}$, José Luis Ríos ${ }^{\mathrm{e}, *}$ \\ a Cátedra de Farmacología Básica, Facultad de Ciencias Médicas, Universidad Nacional de La Plata, CIC Provincia de Buenos Aires, La Plata, Argentina \\ ${ }^{\mathrm{b}}$ Centro de Investigaciones Cardiovasculares, Universidad Nacional de La Plata-CONICET, La Plata, Argentina \\ ${ }^{c}$ Natraceutical Group, Autovía A-3, Salida 343, Camino de Torrent s/n, Quart de Poblet, 46930 Valencia, Spain \\ ${ }^{\mathrm{d}}$ Instituto de Agroquímica y Tecnología de los Alimentos, Consejo Superior de Investigaciones Científicas, 46100 Burjassot, Valencia, Spain \\ e Departament de Farmacología, Facultat de Farmàcia, Universitat de València, Av. Vicent Andres Estelles s/n, 46100 Burjassot, Valencia, Spain
}

\section{A R T I C L E I N F O}

\section{Article history:}

Received 5 November 2009

Accepted 29 April 2010

\section{Keywords:}

Theobroma cacao

Cocoa

Antioxidant

Polyphenols

\begin{abstract}
A B S T R A C T
Fermentation and roasting are the main causes of polyphenol degradation during the process for obtaining cocoa products. In the present study, a process for obtaining polyphenol-rich cocoa products on an industrial scale is described. The process avoids the fermentation and roasting steps and includes a step for the inactivation of the enzyme Polyphenol Oxidase (PPO), which helps preserve the polyphenol content present in the raw cocoa bean. In addition, our study evaluates the antioxidant capacity and characterizes the flavonoid profile of the polyphenol-rich cocoa products obtained from the natural polyphenolrich cocoa cake. Using different protocols, we have obtained three cocoa extracts with high polyphenol content, namely extracts A $(167 \mathrm{mg} / \mathrm{g}), \mathrm{B}(374 \mathrm{mg} / \mathrm{g})$ and C $(787 \mathrm{mg} / \mathrm{g})$. The scavenging capacity of the extracts was measured as their ability to bleach the stable radicals DPPH and ABTS $^{+}$while their antioxidant effect was evaluated with the FRAP assay. The results for A, B and C in the DPPH test expressed as Trolox equivalent ( $\mu \mathrm{mol}) / \mathrm{mg}$ dry weight of extract were $0.2,1.4$ and 3.0, respectively; in the ABTS test the results were 1.0, 4.7 and 9.8. The antioxidant capacity expressed as ascorbic acid equivalent $(\mu \mathrm{mol}) / \mathrm{mg}$ dry weight of each product were $17.2,76.1$ and 207.7, respectively. The scavenging properties of cocoa powder against the superoxide anion, $\mathrm{H}_{2} \mathrm{O}_{2}, \mathrm{HClO}$, and peroxynitrite were also determined. The $\mathrm{IC}_{50}$ $(\mu \mathrm{g} / \mathrm{mL})$ values in the hypoxanthine/xanthine oxidase test were $77.5,12.3$ and 10.3 , for A, B and C, respectively, while as an $\mathrm{HOCl}$ scavenger the $\mathrm{IC}_{50}(\mu \mathrm{g} / \mathrm{mL})$ values were $225.4,73.2$ and 21.5 . As a peroxynitrite anion scavenger, only extract $C$ had a relevant effect, with $\mathrm{IC}_{50}(\mu \mathrm{g} / \mathrm{mL})$ values of 76.1 or 110.0 in the absence or presence of bicarbonate. None of the extracts tested showed activity in the hydrogen peroxide test, but $\mathrm{B}$ and $\mathrm{C}$ significantly increased the deoxyribose degradation in the absence of ascorbate. Likewise, none of the extracts inhibited the ferrous or copper chelating activity at $100 \mu \mathrm{g} / \mathrm{mL}$, but they inhibited the lipid peroxidation in brain homogenates and human plasma through non-enzymatic generation systems, with extract $\mathrm{C}$ giving the best $\mathrm{IC}_{50}(\mu \mathrm{g} / \mathrm{mL})$ values: 17.4 and 8.1 against lipid peroxidation in brain homogenates and human plasma, respectively. In conclusion, if the extractive protocol is well characterized, defined and optimized, cocoa could constitute a source of polyphenols for enriching foods, nutraceuticals and alimentary supplements.
\end{abstract}

(c) 2010 Elsevier Ltd. All rights reserved.

\section{Introduction}

Reactive oxygen species (ROS) are involved in the pathogenesis of several human diseases, including asthma (Freeman \& Crapo, 1982; Jarjour \& Calhoun, 1994), rheumatoid arthritis (Odeh, 1997), atherosclerosis (Aviram, 1995; Witztum \& Steinberg, 1991), inflammatory bowel disease (Keshavarzian et al., 1992), Alzheimer's disease (Pitchumoni \& Doraiswamy, 1998), and cancer (Azad, Rojanasakul, \& Vallyathan, 2008; Federico, Morgillo, Tuccillo, Ciardiello, \& Loguercio, 2007). Fortunately, antioxidant

\footnotetext{
* Corresponding author. Tel.: +34 963544973; fax: +34 963544498.

E-mail address: riosjl@uv.es (J.L. Ríos).
}

agents can prevent or heal various pathologies in which ROS are implicated (Huber, Stuchbury, Bürkle, Burnell, \& Münch, 2006; Sheweita, Tilmisany, \& Al-Sawaf, 2005; Victor, Rocha, Esplugues, \& De la Fuente, 2005; Wang, Wen, Huang, Chen, \& Ku, 2006; Yasui \& Baba, 2006). Moreover, there is growing evidence that consumption of certain foods, dietary supplements, or traditional beverages can lead to reductions in some of the parameters of oxidative damage in biological systems (Aruoma, Bahorun, \& Jen, 2003; Jie et al., 2006; Juan, Wenzel, Ruiz-Gutiérrez, Daniel, \& Planas, 2006; Kaplan et al., 2007; Surh, 1999).

Cocoa-derived foods such as cocoa powders, chocolate, and other cocoa-related products are polyphenol-rich foods derived from the fermented, roasted, and industrially processed seeds of 
Theobroma cacao L. (Sterculiaceae). These products, consumed all over the world, are studied for the most part because of the antioxidant and antiradical properties in vitro of some polyphenolic constituents, principally procyanidins and flavan-3-ols (Wollgast \& Anklam, 2000). Phenolics of cocoa, as well as those of other plant species, have been reported in many studies as being bio-active compounds especially noted for their antioxidant, antiradical, and anticarcinogenic properties (Ren, Qiao, Wang, Zhu, \& Zhang, 2003; Sanbongi et al. 1998; Wollgast \& Anklam, 2000).

The antioxidant properties of cocoa have been studied extensively in recent years. Many approaches have been employed, including chemical characterizations of the antioxidant species involved with the aid of HPLC and HPLC-MS (Adamson et al., 1999), in vitro chemical studies to determine the cocoa's ability to scavenge stable radicals such as DPPH' or ABTS.+ (Hatano et al., 2002), and in vitro biological studies and nutrigenomic-based studies to examine the bioavailability of the major compounds of cocoa and their in vivo interaction with cellular or molecular species (Motohashi et al., 1999).

Flavonoid-rich cocoa products and chocolate have been found to possess relevant biological activity (Fisher, Hughes, GerhardHerman, \& Hollenberg, 2003; Heiss et al., 2005; Rein, Paglieroni et al., 2000; Rein, Lotito et al., 2000). Indeed, the consumption of flavanol-rich cocoa has been reported to improve endothelial function (Wang-Polagruto et al., 2006) and reduce pro-inflammatory mediators (Sies, Schewe, Heiss, \& Kelm, 2005), effects that have been directly linked to the presence of procyanidin-derived metabolites in plasma.

The health benefits of cocoa polyphenols as reported in recent studies have increased the interest in obtaining products from cocoa beans not only with high polyphenol, but also with a high flavan-3-ol content. The main flavan-3-ol compounds present in cocoa are the monomers catechin and epicatechin, and the dimer procyanidin B2 (Lamuela-Raventós, Romero-Pérez, Andrés-Lacueva, \& Tornero, 2005). The content of these compounds is important, since a great number of studies have reported that the bioavailability of cocoa polyphenol is strongly related to molecular size, with smaller polyphenols generally being more beneficial. Compounds of low molecular weight are found in higher concentration in the blood and have a better chance of reaching the target organ in the body (Cooper, Donovan, Waterhouse, \& Williamson, 2009). Therefore, it seems that the higher the amounts of monomeric and dimeric flavanols in the cocoa product, the more health benefits the products have.

The polyphenol content in cocoa-derived products is lower than that found in the raw material used in their production. The major flavan-3-ol enantiomer identified in unfermented, dried, unroasted cocoa beans is the (-)-epicatechin compound. Concentrations of (-)-epicatechin content ranging from 36.4 to $43.2 \mathrm{mg}$ were reported in freeze-dried beans from freshly harvested cocoa beans unaffected by any post-harvest treatment (Kim \& Keeney, 1984). However, during the processing of cocoa, significant degradations of (-)-epicatechin and (+)-catechin compounds take place. The main factors contributing to these degradations are fermentation and the high roasting temperatures. In the aerobic fermentation of cocoa, (-)-epicatechin, $(+)$-catechin and anthocyanidin molecules are oxidized and polymerized in the presence of the polyphenol oxydase (PPO) enzyme. These high molecular weight polymers (tannins) have less bioavailability than their precursors. In recent years, research efforts have focused on ways to mitigate or suspend the PPO enzyme activity in cocoa in order to avoid polyphenol oxidation reactions and polymerization. Tomás-Barberán et al. (2007) have evaluated the best conditions for inactivating the PPO enzyme in fresh cocoa beans by applying heat treatments with water. The optimal conditions under which the lowest enzymatic browning of fresh beans occurred were at $95{ }^{\circ} \mathrm{C}$ for $5 \mathrm{~min}$. In the same study, a flavonoid- enriched cocoa powder was prepared and the flavonoid profile was characterized with the aid of HPLC-DAD-MS/MS on a laboratory scale (Tomás-Barberán et al., 2007). Flavanol recoveries of $79 \%$ of (-)-epicatechin, $62 \%$ of (+)-catechin and $80 \%$ of procyanidin B2 have been reported after the inactivation of the PPO enzyme with water vapor at $95{ }^{\circ} \mathrm{C}$ for $5 \mathrm{~min}$ in raw cocoa beans (Cienfuegos-Jovellanos et al., 2007). In another recently published study, no PPO activity was photometrically determined in steamed, non-fermented beans treated at $98^{\circ} \mathrm{C}$ for $30 \mathrm{~min}$ (Bradbury \& Kschonek, 2008). Kattenberg and Willemsen (2003) described the use of microwave heating to prevent PPO activity in unfermented beans. Thus, the flavanol content present in a final cocoa product depends largely on the cocoa beans' post-harvest handling. Since there are no acceptable processing techniques in the conventional cocoa industry to date which avoid polyphenol degradation as a consequence of the high temperatures used, the optimization of such processes is of great interest. One potential application of the resulting flavonoid-rich products would be their application as functional ingredients in the food industry. The high polyphenol content of the cocoa products thus produced would endow them with the polyphenol dosage necessary for the desired health effects without a substantial modification of their organoleptic characteristics. As an example, a human study has demonstrated that $30 \mathrm{mg}$ /day of flavan-3-ols (up to 5-mers) reduces blood pressure in humans (Taubert, Roesen, Lehmann, Jung, \& Schömig, 2007). If that is indeed the case, then as little as $386 \mathrm{mg} /$ day of a cocoa product rich in polyphenols would be sufficient to provide the amount of flavan-3-ols (up to 2-mers) needed to lower blood pressure (CienfuegosJovellanos et al., 2009).

The present work aims to study both the antioxidant capacity and the flavan-3-ol content of polyphenol-rich cocoa products obtained through processing techniques which are not applied in the conventional cocoa industry.

\section{Material and methods}

\subsection{Reagents, solvents, standards}

Standards of (+)-catechin and (-)-epicatechin (Sigma-Aldrich, St. Louis, MO) and procyanidin B1 and procyanidin B2 (Extrasynthese, Genay, France) were used for quantitative determinations. All chemicals and biochemicals were purchased from Sigma-Aldrich while HPLC-grade solvents were purchased from either Scharlab (Barcelona, Spain) or Merck (Darmstadt, Germany).

\subsection{Preparation of polyphenol-rich cocoa products}

Fresh cocoa pods of the Amazonic-Trinitary variety (CCN51 clone) from the Quevedo region in Ecuador were purchased for the preparation of the cocoa products. The fresh pulp was removed manually from the pods in situ. Batches of $136 \mathrm{~kg}$ of depulped beans were thermally treated with water vapor at an internal bean temperature of $95^{\circ} \mathrm{C}$ for $5 \mathrm{~min}$ by immersing the beans in $2500 \mathrm{~L}$ of water to inactivate the enzyme PPO. The beans were then dried at a controlled temperature of $45^{\circ} \mathrm{C}$ until a moisture content of $7 \%$ was reached. The dried beans were cleaned and deshelled with the aid of aspiration to obtain the nibs, which were then partially defatted through physical pressing at a temperature of $55^{\circ} \mathrm{C}$. Upon completion of this process, a natural polyphenol-rich cocoa cake with a butter content of $12 \%$ was obtained.

The polyphenol-rich cocoa cake was then used as a raw material to obtain a cocoa powder (sample $A$ ) and two polyphenol-rich cocoa extracts (samples $B$ and $C$ ). For the cocoa powder production, the cake was thermally treated in an autoclave with a saturated 
flash steam at $121^{\circ} \mathrm{C}$ for $1 \mathrm{~min}$ (SteamLab, Hamburg, Germany). A $2 \mathrm{~kg}$ batch of a cocoa cake (control) was loaded into a chamber prior to the heat treatment in order to assess total polyphenol and flavanol losses. After the heat treatment, the cake was milled and sieved to obtain a cocoa powder with a particle size of less than $75 \mu \mathrm{m}$ (sample $A$ ).

In a small trial, the defatted cocoa cake obtained in the industrial process was extracted by means of a solid-liquid extraction process with a hydro-alcoholic mixture consisting of ethanol $70 \%$. The cocoa cake was extracted at $70^{\circ} \mathrm{C}$ for $2 \mathrm{~h}$ under mechanical stirring, the solid was filtered, and the liquid fraction was recovered. This fraction was then distilled under reduced pressure to remove the solvent, affording an aqueous extract. After drying the liquid extract, a polyphenol-rich cocoa extract was obtained (sample $B$ ).

The remaining liquid aqueous extract was then subjected to an additional purification step consisting of a liquid-liquid extraction with ethyl acetate at a temperature of $50^{\circ} \mathrm{C}$. The aqueous and organic fractions were separated by means of decantation and the organic phase was recovered. After distillation to remove the organic solvent, the product was dried to obtain a purified cocoa extract (sample $C$ ).

Sample $A$ was thus a natural polyphenol-rich cocoa powder while samples $B$ and $C$ were polyphenol-rich cocoa extracts obtained from the natural-rich cocoa cake, with sample $C$ resulting from a purification of sample $B$. This procedure was expanded to an industrial scale to obtain a range of cocoa products (Pasamar, Ibarra, Cienfuegos-Jovellanos, \& Laghi, 2006).

\subsection{Microbial analysis of the polyphenol-rich cocoa powder}

A gram of milled cocoa was added to $100 \mathrm{~mL}$ of peptone solution (Scharlab, Barcelona, Spain) under sterile conditions. Serial dilutions were cultured in Petri dishes containing the specific media for each type of microorganism. Plate Count Agar (PCA, Scharlab) was used to facilitate the total count of mesophilic aerobic microorganisms. The plates were incubated at $30{ }^{\circ} \mathrm{C}$ for $24 \mathrm{~h}$. In the case of total coliform, the culture was grown on ENDO agar (Scharlab) for $72 \mathrm{~h}$ at $37.3^{\circ} \mathrm{C}$ while salmonella was grown on Rambach agar (Merck, Darmstadt, Germany) for $24 \mathrm{~h}$ at $37^{\circ} \mathrm{C}$. The enterobacteriae analysis was performed on Violet Red Bile Dextrose Agar (VRBD, Scharlab) at $37.3^{\circ} \mathrm{C}$ for $24 \mathrm{~h}$. The mold and yeast analysis was carried out on Rose Bengal Chloramphenicol Agar (RBC, Scharlab) at $25^{\circ} \mathrm{C}$ for a minimum of 5 days. The results are reported as colony forming units (cfu) per gram and are the average of at least four measurements.

\subsection{Determination of the total polyphenol content in cocoa products}

Polyphenol-rich cocoa powder (sample $A$ ), cocoa cakes, and the standard cocoa powder $(1 \mathrm{~g})$ were extracted under reflux with $100 \mathrm{~mL}$ of acetone:water (70:30; v:v) at $60^{\circ} \mathrm{C}$ for $2 \mathrm{~h}$. The acetone was then removed under vacuum at $45^{\circ} \mathrm{C}$ (Tomás-Barberán et al., 2007).

Polyphenol-rich cocoa extract (sample $B$ ) was prepared by dissolving $100 \mathrm{mg}$ of sample in water $(100 \mathrm{~mL})$ with the aid of an ultrasonic bath to ensure total dissolution of the sample.

A different polyphenol-rich cocoa extract (sample $C$ ) was prepared by dissolving $100 \mathrm{mg}$ of sample in $4 \mathrm{~mL}$ of acetonitrile with the aid of an ultrasonic bath to ensure total dissolution of the sample, which was then diluted with distilled water to $100 \mathrm{~mL}$. The total polyphenol content was determined with the aid of the Folin-Ciocalteu spectrophotometric method (Singleton \& Rossi, 1965). The results were expressed as catechin equivalents on a wet weight basis.

\subsection{HPLC-DAD analysis of flavanols in cocoa samples}

The flavanol compounds, monomeric units (catechin and epicatechin), and dimeric procyanidins (procyanidins B1 and B2) were identified and quantified with the aid of reverse-phase HPLC-DAD. Sample $A$, cocoa cakes (the control and the treated cake) and the standard cocoa powder, were extracted as previously described (Andrés-Lacueva, Lamuela-Raventós, \& Jáuregui, 2000). The polyphenol-rich cocoa extracts (samples $B$ and $C$ ) were prepared by dissolving $100 \mathrm{mg}$ of each sample in water $(100 \mathrm{~mL})$ in an ultrasonic bath. An additional dilution of $250 \mu \mathrm{L}$ in $1000 \mu \mathrm{L}$ of distilled water was carried out before the injection. All the samples were passed through a $0.45 \mu \mathrm{m}$ PTFE filter (Teknokroma, Barcelona, Spain) before the injection.

Chromatography was performed on an HPLC System Agilent 1100 Series (Agilent Technologies, Waldbronn, Germany) controlled by ChemStation software (Agilent, v.09.03) and equipped with a manual injector (rheodyne 7725), G1379A degasser, G1311A quaternary pump, G1316A column heater, and G1315B diode array detector. Chromatographic separations were performed in reverse phase on a C18 Zorbax Eclipse XDB column measuring $150 \mathrm{~mm} \times 2.1 \mathrm{~mm}$ i.d. with a particle size of $5 \mu \mathrm{m}$ (Agilent Technologies) at a column temperature of $35^{\circ} \mathrm{C}$. The chromatographic separation itself was a modified version of the method described by Tomás-Barberán et al. (2007). Flavanol identification and quantification was carried out using external standards:(+)catechin, (-)-epicatechin, procyanidin B1, and procyanidin B2. The results are reported on a wet basis.

\subsection{Total antioxidant activity}

\subsubsection{2,2-diphenyl-1-pycryl hydrazyl (DPPH) scavenging activity}

Reduction of the stable free radical DPPH was determined with the aid of a modified version of the method described by Cavin, Hostettmann, Dyatmyko, and Potterat (1998). The extracts $(10 \mu \mathrm{L})$ were added to $990 \mu \mathrm{L}$ of $\mathrm{DPPH}$ in methanol $(20 \mathrm{mg} / \mathrm{L})$. The resulting mixtures were then shaken and left for $30 \mathrm{~min}$ at room temperature in the dark, after which the absorbance of the remaining DPPH was measured at $517 \mathrm{~nm}$ against a blank to eliminate the color from the extracts. The results are expressed in $\mu \mathrm{mol}$ trolox/mg of dry weight of the extract.

\subsubsection{2,2'-azino-bis(3-ethylbenzthiazoline-6-sulphonic acid $\left(\right.$ ABTS $\left.^{+}\right)$ scavenging activity}

Reduction of the stable ABTS radical cation was determined with the aid of a modified version of the method described by Pannala, Chan, O'Brien, and Rice-Evans (2001). Briefly, $\left(\right.$ ABTS $^{+}$) was produced by reacting $7 \mathrm{mM}$ of ABTS stock solution with $2.45 \mathrm{mM}$ of potassium persulphate and then allowing the mixture to stand in the dark at room temperature for $12-16 \mathrm{~h}$ before use. The ABTS $^{+}$solution (2 days stable) was then diluted with $5 \mathrm{mM}$ phosphate-buffered saline $(\mathrm{pH} 7.4)$ to an absorbance of $0.70 \pm 0.02$ at $730 \mathrm{~nm}$. The extracts (final concentration: 1$100 \mu \mathrm{g} / \mathrm{mL}, 10 \mu \mathrm{L}$ ) were added to $990 \mu \mathrm{L}$ of ABTS $^{+}$solution and the resulting mixtures were shaken and left for $30 \mathrm{~min}$ at room temperature in the dark. The absorbance of the remaining ABTS $^{+}$ was then measured at $730 \mathrm{~nm}$ against a blank to eliminate the color of the extracts. Results are expressed as $\mu \mathrm{mol}$ trolox/mg of dry weight of the extract.

\subsubsection{Ferric reducing-antioxidant power (FRAP)}

The FRAP assay was carried out to determine the reducing ability of the cocoa extracts with a method adapted from Benzie and Strain (1996). First, FRAP reagent was freshly prepared by mixing $10 \mathrm{mM}$ of 2,4,6-tripyridyl triazine (TPTZ) with $20 \mathrm{mM}$ of ferric 
chloride in a $0.25 \mathrm{M}$ acetate buffer, $\mathrm{pH}$ 3.6. Aliquots of the sample $(100 \mu \mathrm{L})$ were then mixed with $900 \mu \mathrm{L}$ of FRAP reagent and, after a 30 min incubation at room temperature, the absorbance was read at $593 \mathrm{~nm}$ against a blank of distilled water. Results were expressed as $\mu \mathrm{mol}$ ascorbic acid/mg of dry weight of the extract.

\subsection{Metal chelating properties}

The copper chelating properties of the cocoa extracts were assessed as outlined elsewhere (Dillon, Burmi, Lowe, Billington, \& Rahman, 2003). In principle, the method used was based on the reviviscence of xanthine oxidase when pre-inhibited by $\mathrm{CuSO}_{4}$ at $50 \mu \mathrm{M}$. The activity of the liberated xanthine oxidase was then assessed by monitoring the formation of uric acid. Thus, if the extracts were able to chelate $\mathrm{Cu}^{2+}$, the activity of the pre-inhibited xanthine oxidase should be restored. We also examined the ferrous ion chelating ability of the extracts using the method developed by Lopes, Schulman, and Hermes-Lima (1994). Briefly, a reaction mixture containing extract, $\mathrm{FeCl}_{2}(0.1 \mathrm{~mL}, 2 \mathrm{mM})$, and ferroizine $(0.4 \mathrm{~mL}, 5 \mathrm{mM})$ was shaken and incubated for $10 \mathrm{~min}$ at room temperature. The absorbance of the mixture was measured at $562 \mathrm{~nm}$ against a blank. EDTA was used as a reference.

\subsection{Reactive oxygen species}

\subsubsection{Superoxide radical scavenging activity}

Superoxide radical was generated through enzymatic oxidation of hypoxanthine with xanthine oxidase grade I (0.06 U) and was detected by the reduction of nitroblue tetrazolium (NBT), monitored spectrophotometrically at $560 \mathrm{~nm}$. Details of this assay have been described elsewhere (Schinella, Troiani, Dávila, de Buschiazzo, \& Tournier, 2000). The influence of the extracts on the enzyme activity was evaluated by measuring the uric acid formation from xanthine. After incubation $(15 \mathrm{~min})$, the absorbance was measured at $295 \mathrm{~nm}$. Allopurinol was used as a reference.

Superoxide radical generation by polymorphonuclear (PMN) cells. Human PMNs were isolated from heparinized venous blood through sequential dextran sedimentation, differential density sedimentation in Hypaque-Ficoll gradients, and hypotonic lysis of erythrocytes. After centrifugation, the PMN leukocyte-rich pellets were resuspended in Hanks' balanced salt solution. The cytotoxicity of the extracts had previously been measured with the aid of a modified 3-[4,5-dimethylthiazol-2-yl]-2,5-diphenyl-tetrazolium bromide (MTT) colorimetric assay (Mosmann, 1983). For the superoxide generation assay, the protocol described by Montesinos, Úbeda, Terencio, Payá, and Alcaraz (1995) was used. Superoxide release was induced by addition of 12-O-tetradecanoylphorbol 13acetate (TPA; $1 \mu \mathrm{M})$. After incubation $(10 \mathrm{~min})$ at $37^{\circ} \mathrm{C}$, the precipitate was dissolved in dimethyl sulfoxide (DMSO)- $\mathrm{HCl}(95: 5, \mathrm{v} / \mathrm{v})$ and measured with a Labsystem Multiscan MCC/340 (Helsinki, Finland) set at $560 \mathrm{~nm}$.

\subsubsection{Hydroxyl radical-scavenging assay}

The hydroxyl radical-scavenging assay was carried out according to the method described by Halliwell, Gutteridge, and Aruoma (1987). First, hydroxyl radical was generated by incubating a reaction mixture containing $20 \mu \mathrm{M} \mathrm{FeCl}_{3}, 1.4 \mathrm{mM} \mathrm{H}_{2} \mathrm{O}_{2}, 2.8 \mathrm{mM}$ deoxyribose, $2 \mathrm{mM}$ EDTA, and $100 \mu \mathrm{M}$ ascorbate in $1 \mathrm{~mL}$ of $10 \mathrm{mM}$ $\mathrm{KH}_{2} \mathrm{PO}_{4}-\mathrm{KOH}$ buffer (pH 7.4) for $60 \mathrm{~min}$ at $37^{\circ} \mathrm{C}$. Deoxyribose degradation by the hydroxyl radical was then determined with the aid of the thiobarbituric acid (TBA) method. The addition of $2.8 \%$ trichloroacetic acid (TCA) caused the color to develop, after which $1 \%$ TBA was measured spectrophotometrically at $535 \mathrm{~nm}$. This assay was performed in triplicate with DMSO $(20 \mathrm{mM})$ as a reference.

\subsubsection{Scavenging of $\mathrm{H}_{2} \mathrm{O}_{2}$}

The ability of the extract to scavenge $\mathrm{H}_{2} \mathrm{O}_{2}$ was determined with the aid of the method developed by Ruch, Chen, and Klaunig (1989). One milliliter of extract solution prepared in phosphatebuffered saline (PBS) was incubated with $0.6 \mathrm{~mL}$ of $4 \mathrm{mM} \mathrm{H} \mathrm{H}_{2} \mathrm{O}_{2}$ solution (prepared in PBS) for $10 \mathrm{~min}$. The absorbance of the solution was measured at $230 \mathrm{~nm}$ against a blank solution containing the extract without $\mathrm{H}_{2} \mathrm{O}_{2}$. The concentration of $\mathrm{H}_{2} \mathrm{O}_{2}$ was determined spectrophotometrically from absorption at $230 \mathrm{~nm}$ with the molar absorptivity set up $81 \mathrm{M}^{-1} \mathrm{~cm}^{-1}$.

\subsubsection{Potential to scavenge preformed hypochlorous acid (HOCl assay)}

$\mathrm{HOCl}$ was prepared by adjusting the $\mathrm{pH}$ of a $1 \%(\mathrm{v} / \mathrm{v})$ solution of $\mathrm{NaOCl}$ to 6.2 with diluted $\mathrm{H}_{2} \mathrm{SO}_{4}$. The working concentration of the stock solution was determined spectrophotometrically by measuring its absorbance at $235 \mathrm{~nm}$ and applying a molar extinction coefficient of $100 \mathrm{M}^{-1} \mathrm{~cm}^{-1}$ (Weiss, Klein, Slivka, \& Wei, 1982). The reaction mixture contained taurine $(10 \mathrm{mM}), \mathrm{HOCl}(1 \mathrm{mM})$, cocoa powder (various concentrations), and PBS ( $\mathrm{pH} 7.4$ ) at a final volume of $1 \mathrm{~mL}$. The solution was mixed thoroughly and incubated at room temperature for $10 \mathrm{~min}$ after which $10 \mathrm{~mL}$ of $\mathrm{KI}$ were added. The solution turned yellow in color and the absorbance was measured at $350 \mathrm{~nm}$.

\subsubsection{Scavenging of peroxynitrite radical}

2.8.5.1. Peroxynitrite synthesis. Peroxynitrite was synthesized in a quenched flow reactor in accordance with the method described by Koppenol, Kissner, and Beckman (1996). Acidified $\mathrm{H}_{2} \mathrm{O}_{2}(0.6 \mathrm{M}$ in $0.7 \mathrm{M} \mathrm{HCl}, 20 \mathrm{~mL}$ ) was mixed with $\mathrm{NaNO}_{2}(0.6 \mathrm{M}, 20 \mathrm{~mL})$ to form peroxynitrous acid $(\mathrm{ONOOH})$, which was then stabilized with $\mathrm{NaOH}(1.5 \mathrm{M}, 40 \mathrm{~mL})$ to give sodium peroxynitrite. The excess of $\mathrm{H}_{2} \mathrm{O}_{2}$ was removed by mixing the solution with $\mathrm{MnO}_{2}$. The solution was filtered and frozen at $-20^{\circ} \mathrm{C}$ for less than 2 weeks. The concentration of $\mathrm{ONOO}^{-}$was determined upon measuring the absorbance at $302 \mathrm{~nm}\left(\varepsilon=1670 \mathrm{M}^{-1} \mathrm{~cm}^{-1}\right)$.

2.8.5.2. Pyrogallol bleaching assay for peroxynitrite scavenging. The pyrogallol red bleaching assay was carried out as reported by Balavoine and Geletii (1999). Briefly, the assay was performed at $25^{\circ} \mathrm{C}$ in phosphate buffer ( $100 \mathrm{mM}$, pH 7.0) containing $50 \mu \mathrm{M}$ pyrogallol red and increasing concentrations of extracts, with or without $25 \mathrm{mM}$ of $\mathrm{NaHCO}_{3}$. The reaction commenced with the addition of $25 \mu \mathrm{M}$ of $\mathrm{ONOO}^{-}$and was mixed immediately. After $5 \mathrm{~min}$, the decrease in the absorbance at $542 \mathrm{~nm}$ was recorded.

\subsection{Inhibition of lipid peroxidation}

\subsubsection{Assays with brain homogenates}

For the in vitro studies, the brains of normal rats were dissected and homogenized with a Polytron (speed setting 7-8) in ice-cold Tris- $\mathrm{HCl}$ buffer $(20 \mathrm{mM}, \mathrm{pH} 7.4)$ to produce a $1 / 10$ homogenate. The homogenate was centrifuged at $10,000 \mathrm{~g}$ for $30 \mathrm{~min}$. One milliliter aliquots of the supernatant were then incubated with the test samples in the presence of $10 \mu \mathrm{M} \mathrm{FeSO}_{4}$ and $0.1 \mathrm{mM}$ ascorbic acid at $37^{\circ} \mathrm{C}$ for $1 \mathrm{~h}$. The reaction was halted upon adding $1.0 \mathrm{~mL}$ TCA $(28 \%, \mathrm{w} / \mathrm{v})$ and $1.5 \mathrm{~mL}$ TBA $(1 \%, \mathrm{w} / \mathrm{v})$ in succession, after which the solution was heated to $100{ }^{\circ} \mathrm{C}$ for $15 \mathrm{~min}$. After centrifugation to remove precipitated protein, the characteristic color of the malondialdehyde (MDA)-TBA complex was detected at $532 \mathrm{~nm}$ (Liu \& Ng, 2000; Ng, Liu, \& Wang, 2000).

\subsubsection{Plasma oxidation}

Hundred microliter of heparin plasma $(200 \mu \mathrm{g} \pm 20 \mu \mathrm{g}$ total cholesterol) was diluted with $350 \mu \mathrm{L}$ of PBS and the oxidation was begun by adding $50 \mu \mathrm{L}$ of $\mathrm{CuSO}_{4}$ at $10 \mathrm{mM}$. After $150 \mathrm{~min}$ of incubation at $37{ }^{\circ} \mathrm{C}$, EDTA was added to stop the reaction. TBA reac- 
tive species (TBARS) were determined as previously described (Schinella et al., 2007).

\section{Results}

\subsection{Obtaining polyphenol-rich cocoa products}

The process for obtaining polyphenol-rich cocoa products on an industrial scale is summarized in Fig. 1.

\subsection{Microbiological analysis of polyphenol-enriched cocoa powder}

An astringent and purple cocoa powder with high procyanidin content was obtained as previously reported, albeit on a laboratory, not an industrial, scale (Tomás-Barberán et al., 2007). This

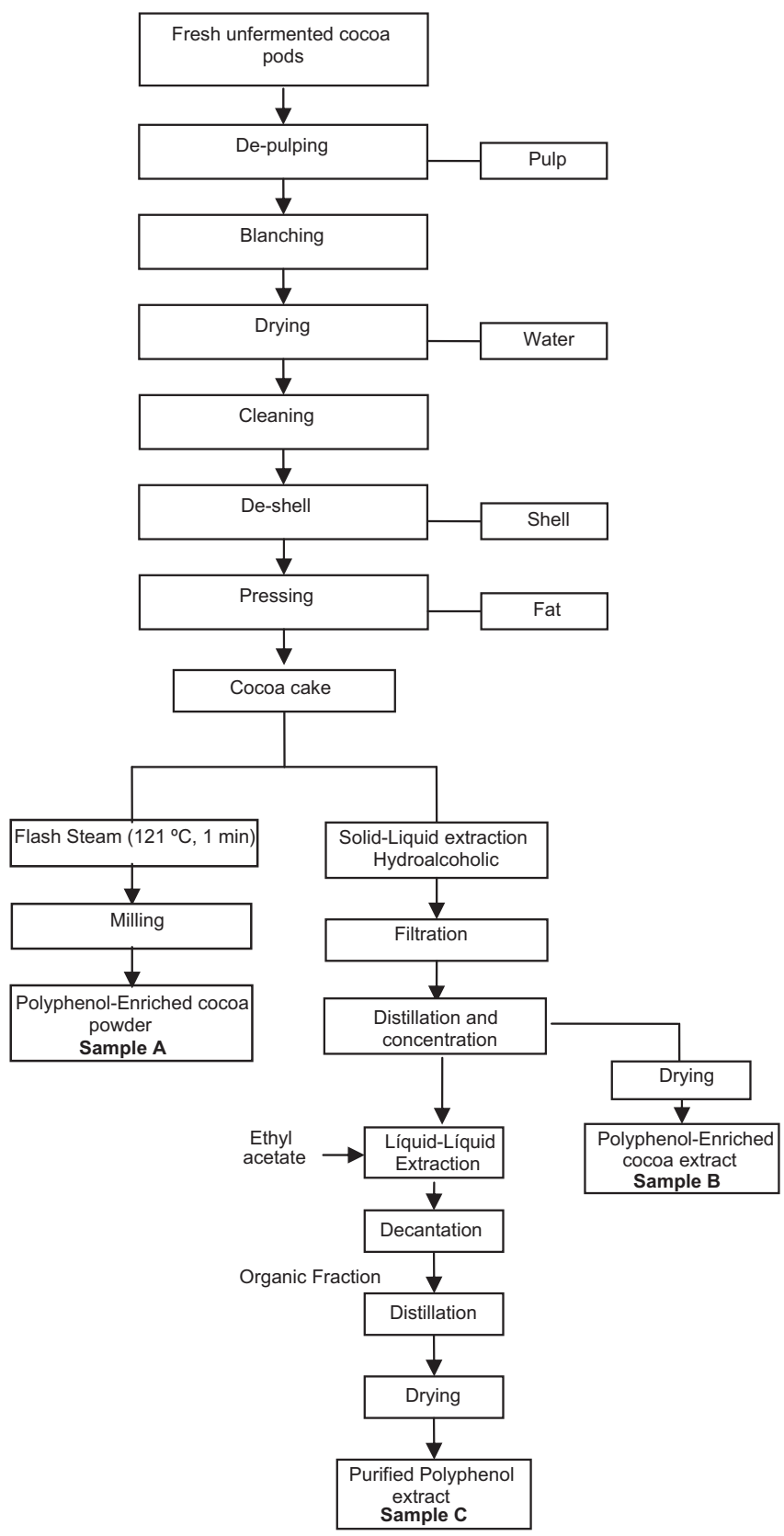

Fig. 1. Flow-chart of the process for obtaining polyphenol-rich cocoa products at industrial scale. powder meets the requirements of the standard legislation as to its content of microbial elements: total microorganisms $<5000$, molds and yeast $<100$, enterobacteriae $<10$, and total absence of Escherichia coli and Salmonella sp.

\subsection{Determination of total polyphenols of polyphenol-rich cocoa products}

The total polyphenol content and the flavanol profile (catechin, epicatechin, and procyanidins B1 and B2) analyzed in the final products (samples $A-C$ and standard cocoa powder), and in the intermediate products (control and steamed cake) are summarized in Tables 1 and 2, respectively.

\subsection{Chromatographic profile of samples A-C}

The final products (samples $A-C$ ) were analyzed with the aid of HPLC. The major phenolic compounds (catechin, epicatechin, and procyanidins B1 and B2) were identified as was the presence of methylxanthines (Fig. 2A-C). Other relevant dimers such as procyanidin $B_{5}$ present in the cocoa products were not detected. This was also the case with trimers and tetramers.

\subsection{Antioxidant activity}

The antioxidant capacity of plant extracts depends largely on their composition and the conditions of the test system used. As both of these are influenced by many factors, the antioxidant effects cannot be fully characterized with one single method. It is thus necessary to perform more than one type of antioxidant capacity measurement to take into account the various mechanisms that contribute to the antioxidant action. We therefore employed several different methods to assess the antioxidant activity of the samples.

Table 1

Total polyphenols and flavanol profile of the standard cocoa powder, polyphenol-rich cocoa powder (sample $A$ ) and cocoa extracts (samples $B$ and $C$ ).

\begin{tabular}{|c|c|c|c|c|}
\hline Sample & $\begin{array}{l}\text { Standard cocoa } \\
\text { powder }(\mathrm{mg} / \mathrm{g})\end{array}$ & $A(\mathrm{mg} / \mathrm{g})$ & $B(\mathrm{mg} / \mathrm{g})$ & $C(\mathrm{mg} / \mathrm{g})$ \\
\hline Total polyphenols (catechin) ${ }^{\mathrm{a}}$ & 50 & 167 & 374 & 787 \\
\hline$(+)$-Catechin ${ }^{\mathrm{b}}$ & 1.20 & 4.87 & 25.06 & 117.45 \\
\hline (-)-Epicatechin ${ }^{\mathrm{b}}$ & 0.67 & 19.43 & 62.19 & 300.73 \\
\hline Procyanidin $\mathrm{B} 1^{\mathrm{b}}$ & 0.11 & 1.18 & 2.72 & 7.65 \\
\hline Procyanidin $\mathrm{B}^{\mathrm{b}}$ & 0.17 & 10.79 & 21.24 & 63.76 \\
\hline Total sum & 2.15 & 36.27 & 111.21 & 489.59 \\
\hline
\end{tabular}

${ }^{a}$ Results are expressed on wet basis and as catechin equivalents.

b Data obtained using reverse-phase HPLC. Data are average of duplicate test.

Table 2

Total polyphenols and flavanol profile of the intermediate products (control and steamed cake).

\begin{tabular}{lll}
\hline Sample & $\begin{array}{l}\text { Control (cake before } \\
\text { treatment) }(\mathrm{mg} / \mathrm{g})\end{array}$ & $\begin{array}{l}\text { Steamed cake (after } \\
\left.\text { treatment } 121^{\circ} \mathrm{C} / 1 \mathrm{~min}\right) \\
(\mathrm{mg} / \mathrm{g})\end{array}$ \\
\hline Total polyphenols (catechin) $^{\mathrm{a}}$ & 183.4 & 181.7 \\
(+)-Catechin $^{\mathrm{b}}$ & 4.97 & 4.00 \\
(-)-Epicatechin $^{\mathrm{b}}$ & 20.96 & 20.47 \\
Procyanidin B1 $^{\mathrm{b}}$ & 1.12 & 0.51 \\
Procyanidin B2 $^{\mathrm{b}}$ & 12.46 & 12.88 \\
Total sum $^{\mathrm{b}}$ & 39.51 & 37.86 \\
\hline
\end{tabular}

\footnotetext{
a Results are expressed on wet basis and as catechin equivalents.

b Data obtained using reverse-phase HPLC-DAD. Data are average of duplicate
} test. 

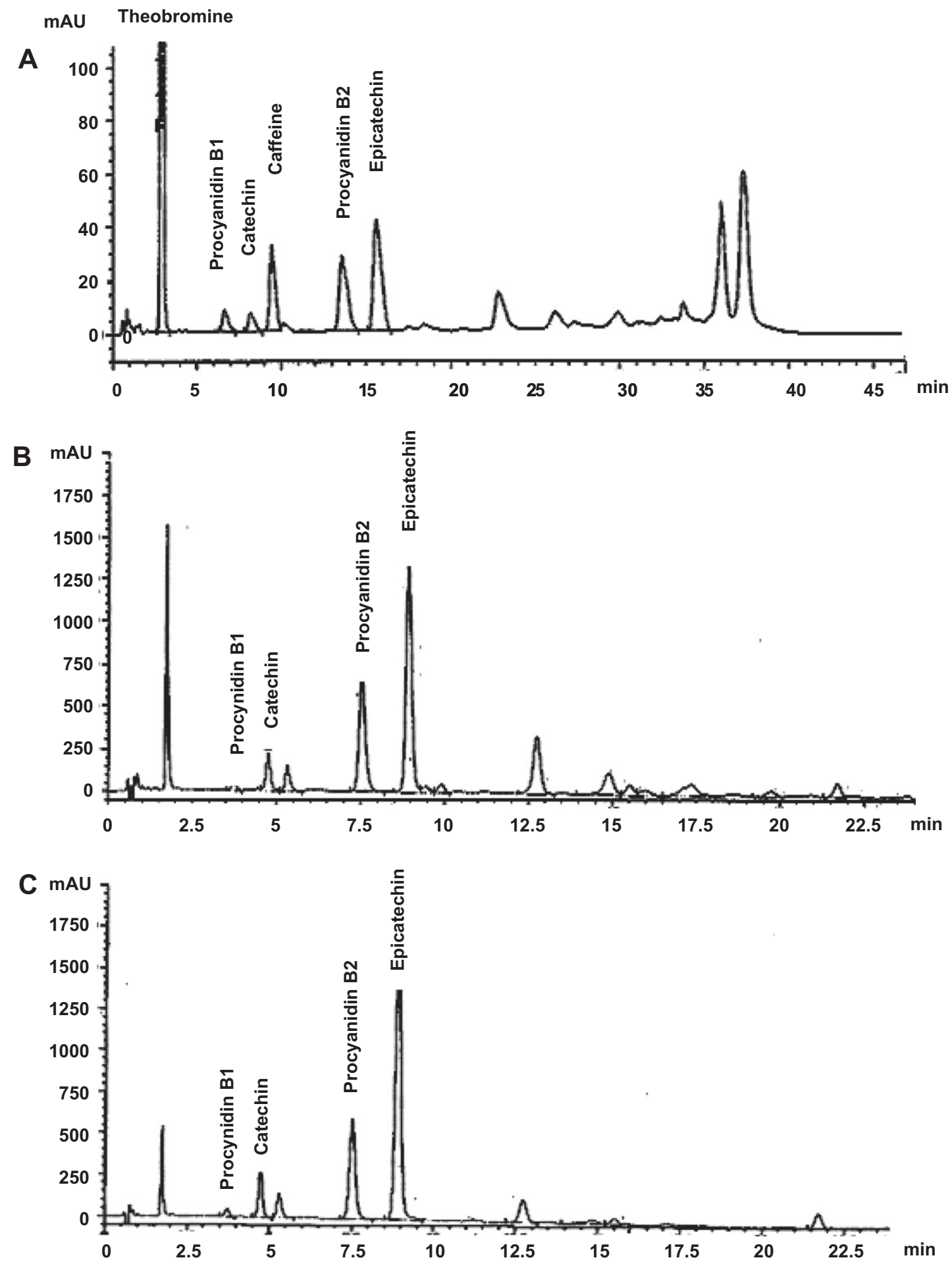

Fig. 2. Reverse-phase HPLC-DAD chromatogram of flavanols from polyphenol-rich cocoa powder (samples $A-C$ ).

We first examined the aqueous soluble fraction of a mixture of extracts $(10 \mathrm{mg} / \mathrm{mL})$ to determine antioxidant activity. The scavenging capacity of the extracts was measured as the ability to bleach the stable radicals DPPH' and $\mathrm{ABTS}^{+}$; the results are compiled in Table 3. The FRAP assay, in contrast, measures the antioxidant effect of any substance in the reaction medium as its reducing ability, with the values for activity expressed as ascorbic acid equivalents in the extract (Table 3 ).

The scavenging properties of cocoa powder against the superoxide anion, $\mathrm{H}_{2} \mathrm{O}_{2}, \mathrm{HClO}$, and peroxynitrite were then determined; the $\mathrm{IC}_{50}$ values are listed in Table 4 . At a final concentration of $100 \mu \mathrm{g} / \mathrm{mL}$, none of the extracts were able to scavenge the hydroxyl radical produced in the $\mathrm{Fe}^{3+}$-EDTA $+\mathrm{H}_{2} \mathrm{O}_{2}$ system in the presence or absence of ascorbate. Moreover, we observed a significant increase in deoxyribose degradation caused by extracts $B$ and $C$ in the absence of ascorbate (Fig. 3 ).

Likewise at $100 \mu \mathrm{g} / \mathrm{mL}$, the polyphenol-rich cocoa extracts exhibited no ferrous or copper chelating activity (data not shown). We also evaluated the ability of the cocoa powder to bring about lipid peroxidation in brain homogenates and human plasma using 
Table 3

Total antioxidant activity of cocoa powder.

\begin{tabular}{lllr}
\hline Sample & DPPH $^{\mathrm{a}}$ & ABTS $^{+\mathrm{a}}$ & FRAP $^{\mathrm{b}}$ \\
\hline A & 0.2 & 1.0 & 17.2 \\
B & 1.4 & 4.7 & 76.1 \\
C & 3.0 & 9.8 & 207.7 \\
\hline
\end{tabular}

a Results are expressed as Trolox equivalent $(\mu \mathrm{mol}) / \mathrm{mg}$ dry weight of extract.

b Results are expressed as ascorbic acid equivalent $(\mu \mathrm{mol}) / \mathrm{mg}$ dry weight of extract.

Table 4

Reactive oxygen species scavenging properties of cocoa powder.

\begin{tabular}{llllllll}
\hline Sample & $\mathrm{O}_{2}^{-\mathrm{a}}$ & & & $\mathrm{H}_{2} \mathrm{O}_{2}{ }^{\mathrm{a}}$ & $\mathrm{HOCl}^{\mathrm{a}}$ & & \multicolumn{2}{l}{$\mathrm{ONOO}^{-\mathrm{a}}$} & \\
\cline { 2 - 3 } \cline { 7 - 8 } & $\mathrm{b}$ & $\mathrm{c}$ & & & & $\mathrm{d}$ & $\mathrm{e}$ \\
\hline $\mathrm{A}$ & 77.5 & $>400$ & $>100$ & 225.4 & $>400$ & $>400$ \\
$\mathrm{~B}$ & 12.3 & 372.4 & $>100$ & 73.2 & 144.7 & 255.7 \\
$\mathrm{C}$ & 10.3 & 315.9 & $>100$ & 21.5 & 76.1 & 110.0
\end{tabular}

a Results are expressed as $\mathrm{IC}_{50}$ values $(\mu \mathrm{g} / \mathrm{mL})$.

b Hypoxanthine/xanthine oxidase/NBT.

c $\mathrm{PMN} / \mathrm{TPA} / \mathrm{NBT}$.

d Without $\mathrm{NaHCO}_{3}$.

e With $\mathrm{NaHCO}_{3}$.

non-enzymatic generation systems. We found that the extracts inhibited lipid peroxidation in both the homogenates and the plasma. The results are summarized in Table 5.

\section{Discussion}

Oxygen radicals and lipid peroxides are implicated in various physiological and pathological disorders, including those affecting the neurological, ocular, endocrine, vascular, hemolytic, renal, hepatic, autoimmune, pulmonary and gastrointestinal systems, as well as in neoplasia, aging, inflammation, apoptosis, obesity, and
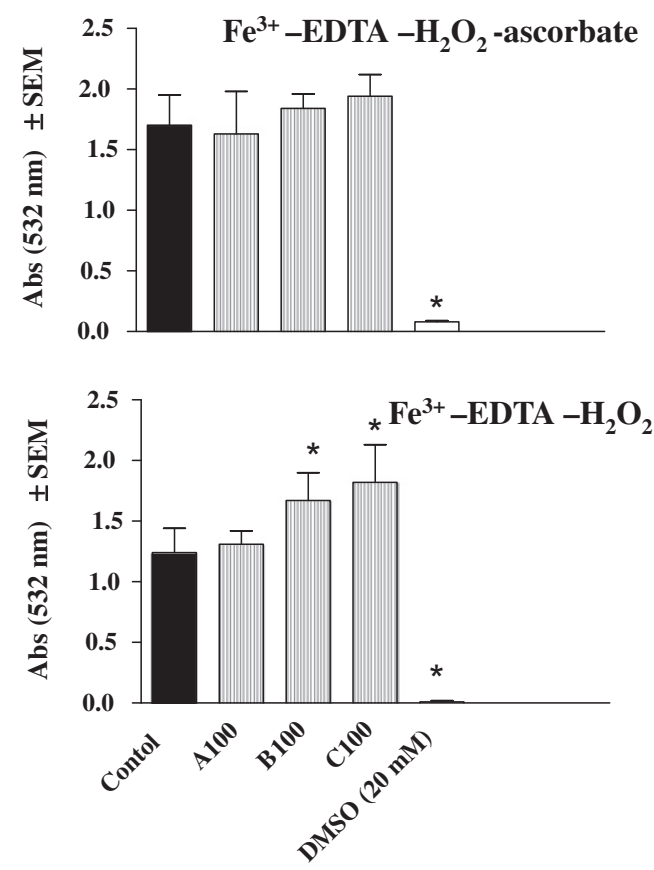

Fig. 3. Effects of cocoa samples $A-C$ at a final concentration of $100 \mu \mathrm{g} / \mathrm{mL}$ on hydroxyl radical produced in the $\mathrm{Fe}^{3+}-\mathrm{EDTA}-\mathrm{H}_{2} \mathrm{O}_{2}$ system in the presence or absence of ascorbate. DMSO was used as a positive control.
Table 5

Inhibition of lipid peroxidation by cocoa powder.

\begin{tabular}{lll}
\hline Sample & $\mathrm{Fe}^{2+} /$ ascorbate/brain homogenate $^{\mathrm{a}}$ & $\mathrm{Cu}^{2+} /$ plasma $^{\mathrm{a}}$ \\
\hline $\mathrm{A}$ & $>100$ & 57.3 \\
$\mathrm{~B}$ & 35.6 & 15.1 \\
$\mathrm{C}$ & 17.4 & 8.1 \\
\hline
\end{tabular}

${ }^{\text {a }}$ Results are expressed as $\mathrm{IC}_{50}$ values $(\mu \mathrm{g} / \mathrm{mL})$.

other phenomena (Armstrong, 1998). The implication of redox mechanisms in these human diseases and aging has led to the suggestion that antioxidants, in particular, plant diet-derived antioxidants, might have health benefits as prophylactic agents (Aruoma, 2003). However, even after many clinical trials, the health benefits of antioxidant compounds for humans have not been demonstrated. There are various elements involved in this "antioxidant paradox," which has recently been analyzed by Halliwell. For example, the use of high doses of antioxidants may actually be detrimental, with lower doses being more beneficial, as is the case with tocopherols and carotenoids (Halliwell, 2009). Moreover, the potential value of antioxidants is often low due to their low levels in cells and tissue, thus limiting their possible use as therapeutic drugs. For example, in the therapeutic strategies to prevent progressive neuronal loss based on antioxidant activity, the antioxidant must be able to cross the blood brain barrier and be present at the respective brain region for neuroprotection (Aruoma, 2003). That being said, food, nutraceuticals, and complementary medicines facilitate the administration or ingestion of high quantities of antioxidant compounds, which can produce high or moderate levels of antioxidant agents in the blood and tissue. This protects the natural antioxidants from destruction and consequently reduces cell and tissue damage (Heinrich \& Prieto, 2008).

To date, numerous studies on the antioxidant activity of plant extracts have been published. Of these, Lee, Kim, Lee, and Lee (2003) compared the antioxidant effects of cocoa water extract against water extract obtained from red wine and green and black tea. These authors observed high activity for the cocoa extract in both ABTS and DPPH tests, most likely due to a high content in phenolics. Previously, Waterhouse, Shirley, and Donovan (1996) had demonstrated that the extractive method used for preparing various extracts affects the total phenol and flavonoid content, which, in turn, has an effect on a given extract's antioxidant properties. Moreover, it is likely that different experimental protocols may also modify the antioxidant activity (Schlesier, Harwat, Bohm, \& Bitsch, 2002). In our experiments, there was a clear correlation between the enriched samples and their antioxidant activities. Thus, sample $C$ has the best $\mathrm{IC}_{50}$ value as both a free radical scavenger (DPPH, ABTS, superoxide, hypochloride, and peroxinitrite) and a lipid peroxidation inhibitor. These effects increased in direct proportion to the content of polyphenols in the extract. Samples $B$ and $C$ presented a higher FRAP and pro-oxidant effect in the $\mathrm{Fe}^{3+}$ EDTA- $\mathrm{H}_{2} \mathrm{O}_{2}$ system, which can be directly attributed to the recognized efficacy of phenolic compounds in the redox recycling of iron (Burkitt \& Gilbert, 1990). The cocoa extracts were also active in the inhibition of superoxide production by PMNL. These results reflect those obtained for the assay for superoxide generation in cell-free systems. Taken together, these findings indicate that the cocoa extracts act by exerting activity on some of the biological functions of PMNL that are implicated in the initiation and maintenance of inflammation (Góngora et al., 2002). In addition, our extracts showed scavenging activity against peroxynitrite in both the presence and absence of a physiological concentration of bicarbonate. It is well-known that the peroxynitrite anion can attack a wide range of biological molecules. The chemistry of $\mathrm{ONOO}^{-} / \mathrm{ONOOH}$ is further complicated by the formation of an adduct between $\mathrm{ONOO}^{-}$and 
$\mathrm{CO}_{2}\left(\mathrm{ONOOCO}_{2}^{-}\right)$, the decomposition of which results in the formation of a carbonate radical anion $\left(\mathrm{CO}_{3}{ }^{-}\right)$and $\mathrm{NO}_{2}$. or a nitronium/ carbonate ion pair. Under physiological conditions, the levels of bicarbonate $\left(\mathrm{HCO}_{3}^{-}\right)$are high and significant yields of $\mathrm{ONOOCO}_{2}^{-}$ can be produced; however, in inflamed tissues where the $\mathrm{pH}$ value is lower, different reactions independent of the presence of $\mathrm{CO}_{2}$ may occur (Kennetta \& Davies, 2007).

Oxidation of unsaturated fatty acids in biological membranes leads to the formation and propagation of lipid radicals, oxygen uptake, rearrangement of the double bonds in unsaturated lipids, and the eventual destruction of membrane lipids resulting in breakdown products such as malondialdehyde. Antioxidative materials acting in living systems are classified as either preventive antioxidants or chain-breaking ones. In the present study, polyphenol-rich cocoa extracts inhibited the non-enzymatic lipid peroxidation in rat brain homogenates, but they had no effect on the hydroxyl radical, nor did they exhibit ferrous chelating activity. Metal chelating capacity reduces the concentration of the catalyzing transition metal in lipid peroxidation. It has previously been reported that the chelation efficiency of some compounds with a phenyl group on $\mathrm{Fe}^{2+}$ is dependent on the number of hydroxyl groups on the benzene ring, and that hydroxyl substitution in the ortho position results in a higher chelating effect (Yen, Duh, \& Chuang, 2000). However, the polyphenol-rich cocoa extracts showed neither ferrous nor copper chelating activity. They must therefore act as chain-breaking antioxidants. These properties could be of great interest in cardiovascular disease prevention therapies because oxidative modification of LDL appears to be crucial for atherogenesis (Sies et al., 2005). The same authors demonstrated that cocoa polyphenols decreased the plasma concentration of pro-inflammatory cysteinyl leukotrienes through inhibition of 5-lipoxygenase, thus suppressing lipid peroxidation in LDL. Moreover, they demonstrated that cocoa phenols promote the bioactivity of nitric oxide in vivo, which is critical for protecting the cardiovascular system.

In a double-blind, randomized trial with 22 heart transplant recipients, Flammer et al. (2007) studied the effect of the ingestion of dark chocolate ( $70 \%$ cocoa) on coronary vascular and platelet function and demonstrated that phenolic-rich dark chocolate induces coronary vasodilatation, improves coronary vascular function by increasing the bioavailability of nitric oxide, and decreases platelet adhesion. These effects were parallel to a reduction of serum oxidative stress and positively correlated with changes in serum epicatechin concentration. The authors went onto postulate a potential beneficial effect of polyphenols with regard to atherothrombosis and cardiovascular disease. In our case, the samples have even higher polyphenol concentrations and less fat and glucose.

Much attention has been devoted to the effect of these antioxidants on lipoprotein peroxidation induced by copper ex vivo (Gaut \& Heinecke, 2001). Our studies reveal that the polyphenol-rich cocoa extracts inhibit the lipid peroxidation of plasmatic lipoproteins (Table 5). The mechanisms by which $\mathrm{Cu}^{2+}$ ions initiate and propagate the oxidation of LDL involve both $\alpha$-tocopheroxyl ( $\alpha$-Toc-O*) and hydroxyl $\left(\mathrm{OH}^{*}\right)$ radicals, both of which may be responsible for the initiation of polyunsaturated fatty acid oxidation (Horsley et al., 2007). At $100 \mu \mathrm{g} / \mathrm{mL}$, the polyphenol-rich cocoa extracts exhibited no copper chelating activity, nor did they show any apparent hydroxyl radical scavenging activity. The antioxidant property of these extracts in copper-induced plasma oxidation may thus be explained by the chain-breaking activity of polyphenols, which act as H-donors to the peroxy radical and provoke the termination of radical chain reactions.

The results of studies on the bioavailability of cocoa polyphenols in vivo have been contradictory at best. Still, Rios, Bennet, Lazarus, Rémésy, and Scalbert (2002) reported on the stability of procyanidins during gastric transit in humans while Holt et al.
(2002) detected procyanidin dimer B2 $(41 \mathrm{nmol} / \mathrm{L})$ in human plasma $2 \mathrm{~h}$ after the consumption of an enriched sample of cocoa (256 mg). Notwithstanding, other derivatives are detected in higher values (epicatechin $5.92 \mu \mathrm{g} / \mathrm{mL}$ and catechin $0.16 \mu \mathrm{g} / \mathrm{mL}$ ). These values are within the range of activity showed in vitro by these compounds (Hatano et al., 2002), which are in concordance with the values obtained in our experiments.

The total polyphenols and flavanols quantified in the cocoa powder rich in polyphenols (sample $A$ ) were much higher than the standard cocoa powder (Table 1), but similar to those found in another previously reported cocoa polyphenol (CienfuegosJovellanos et al., 2009). Furthermore, after the extraction process, the cocoa extract (sample $B$ ) contained three times more epicatechin and five times more procyanidin $\mathrm{B} 2$ than its respective control (the cocoa cake before treatment). The purification step resulted in a concentration of epicatechin monomer of $300 \mathrm{mg} / \mathrm{g}$. The high amount of these flavanols of low molecular weight, especially the monomer (-)-epicatechin, is thought to be important because an increase in plasma (-)-epicatechin is accompanied by a dosedependent increase in plasma antioxidant capacity (Rein, Paglieroni et al., 2000; Rein, Lotito et al., 2000; Serafini et al., 2003), and a dose-dependent decrease in plasma lipid oxidation (Rein, Paglieroni et al., 2000; Rein, Lotito et al., 2000). According to the results shown in Table 2, applying a heat treatment of $121^{\circ} \mathrm{C}$ for $1 \mathrm{~min}$ did not result in any loss of total monomers and dimers as quantified by means of HPLC-DAD. The results confirm that the wet heat treatment produces polyphenol-rich cocoa powder that meets the microbiological standards for its commercialization without altering the phenolic composition. The differences observed in the total polyphenol and flavan-3-ol content of the standard cocoa powder as compared to that found in the polyphenol-rich cocoa products indicate the importance of the production process in the preservation of polyphenol from the original cocoa.

In conclusion, these cocoa products may constitute an important source of polyphenols to serve as functional ingredients for the food and cosmetics industries if the extractive protocol is characterized and defined in advance to obtain values of catechin, epicatechin, and procyanidin in ranges that would allow them to reach physiologically active values in the blood and tissue. In parallel, the development and validation of biological markers could be of great interest to determine the efficacy of dietary antioxidants.

\section{Acknowledgements}

We thank Mr. D. Fioravanti, Ms. Y. Castilla and Ms. M. Climent for their helpful technical assistance.

\section{References}

Adamson, G. E., Lazarus, S. A., Mitchell, A. E., Prior, R. L., Cao, G., Jacobs, P. H., et al. (1999). HPLC method for the quantification of procyanidins in cocoa and chocolate samples and correlation to total antioxidant capacity. Journal of Agricultural and Food Chemistry, 47, 4184-4188.

Armstrong, D. (1998). Preface. In D. Armstrong (Ed.), Free radicals and antioxidant protocols. Totowa, New Jersey: Humana Press.

Andrés-Lacueva, C., Lamuela-Raventós, R. M., \& Jáuregui, O. (2000). An LC method for the analysis of cocoa phenolics. LC GC Europe, 902-905.

Aruoma, O. I. (2003). Methodological considerations for characterizing potential antioxidant actions of bioactive components in plant foods. Mutation Research, 523-524, 9-20.

Aruoma, O. I., Bahorun, T., \& Jen, L. S. (2003). Neuroprotection by bioactive components in medicinal and food plant extracts. Mutation Research, 544, 203-215.

Aviram, M. (1995). Oxidative modification of low density lipoprotein and its relation to atherosclerosis. Israel Journal of Medical Sciences, 31, 241-249.

Azad, N., Rojanasakul, Y., \& Vallyathan, V. (2008). Inflammation and lung cancer: Roles of reactive oxygen/nitrogen species. Journal of Toxicology and Environmental Health. Part B, Critical Reviews, 11, 1-15.

Balavoine, G. G., \& Geletii, Y. V. (1999). Peroxynitrite scavenging by different antioxidants. Part I: Convenient assay. Nitric Oxide, 3, 40-54. 
Benzie, I. F. F., \& Strain, J. J. (1996). The ferric reducing ability of plasma (FRAP) as a measure of "antioxidant power": The FRAP assay. Analytical Biochemistry, 239, 70-76.

Bradbury, A. G. W., \& Kschonek, E. M. (2008). Cocoa beans with reduce polyphenol oxidase activity and high polyphenol content. EP2005835 (A1). USA: Kraft Foods R\&D Inc.

Burkitt, M. J., \& Gilbert, B. C. (1990). Model studies of the iron-catalysed HaberWeiss cycle and the ascorbate-driven Fenton reaction. Free Radical Research Communications, 10, 265-280.

Cavin, A., Hostettmann, K., Dyatmyko, W., \& Potterat, O. (1998). Antioxidant and lipophilic constituents of Tinospora crispa. Planta Medica, 64, 393-396.

Cienfuegos-Jovellanos, E., Pasamar, M. A., Fritz, J., Arcos, J., Ramón, D., \& Castilla, Y. (2007). Proceso de obtención de cacao en polvo rico en polifenoles y bajo contenido en materia grasa, y cacao así obtenido. Patent Cooperation Treaty (PCT) WO 2007/096449A1. Spain: Natraceutical Industrial.

Cienfuegos-Jovellanos, E., Quiñones, M. M., Muguerza, B., Moulay, L., Miguel, M., \& Aleixandre, A. (2009). Antihypertensive effect of a polyphenol-rich cocoa powder industrially processed to preserve the original flavonoids of the cocoa beans. Journal of Agricultural and Food Chemistry, 57, 6156-6162.

Cooper, K. A., Donovan, J. L., Waterhouse, A. L., \& Williamson, G. (2009). Cocoa and health: A decade of research. British Journal of Nutrition, 99, 1-11.

Dillon, S. A., Burmi, R. S., Lowe, G. M., Billington, D., \& Rahman, K. (2003). Antioxidant properties of aged garlic extract: An in vitro study incorporating human low density lipoprotein. Life Sciences, 2003(72), 1583-1594.

Federico, A., Morgillo, F., Tuccillo, C., Ciardiello, F., \& Loguercio, C. (2007). Chronic inflammation and oxidative stress in human carcinogenesis. International Journal of Cancer, 121, 2381-2386.

Fisher, N. D. L., Hughes, M., Gerhard-Herman, M., \& Hollenberg, N. K. (2003). Flavonoid-rich cocoa induces nitric-oxide-dependent vasodilation in healthy humans. Journal of Hypertension, 21, 2281-2286.

Flammer, A. J., Hermann, F., Sudano, I., Spieker, L., Hermann, M., Cooper, K. A., et al. (2007). Dark chocolate improves coronary vasomotion and reduces platelet reactivity. Circulation, 116, 2376-2382.

Freeman, B. A., \& Crapo, J. D. (1982). Biology of disease: Free radicals and tissue injury. Laboratory Investigation, 47, 412-426.

Gaut, J. P., \& Heinecke, J. W. (2001). Mechanisms for oxidizing low-density lipoprotein. Insights from patterns of oxidation products in the artery wall and from mouse models of atherosclerosis. Trends in Cardiovascular Medicine, $11,103-112$.

Góngora, L., Giner, R. M., Máñez, S., Recio, M. C., Schinella, G., \& Ríos, J. L. (2002). Effects of caffeoyl conjugates of isoprenyl-hydroquinone glucoside and quinic acid on leukocyte function. Life Sciences, 71, 2995-3004.

Halliwell, B. (2009). The wanderings of a free radical. Free Radicals in Biology and Medicine, 46, 531-542.

Halliwell, B., Gutteridge, J. M. C., \& Aruoma, O. I. (1987). The deoxyribose method: Simple "test-tube" assay for determination of rate constants for reactions of hydroxyl radicals. Analycal Biochemistry, 165, 215-219.

Hatano, T., Miyatake, H., Natsume, M., Osakabe, N., Takizawa, T., Ito, H., et al. (2002). Proanthocyanidin glycosides and related polyphenols from cacao liquor and their antioxidant effects. Phytochemistry, 59, 749-758.

Heinrich, M., \& Prieto, J. M. (2008). Diet and healthy ageing 2100: Will we globalise local knowledge systems? Ageing Research Review, 7, 249-274.

Heiss, C., Kleinbongard, P., Dejam, A., Perre, S., Schroeter, H., Sies, H., et al. (2005). Acute consumption of flavanol-rich cocoa and the reversal of endothelial dysfunction in smokers. Journal of the American College of Cardiology, 46, 1276-1283.

Holt, R. R., Lazarus, S. A., Sullards, M. C., Zhu, Q. Y., Schramm, D. D., Hammerstone, J.

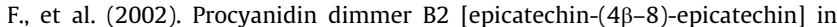
human plasma after consumption of a flavanol-rich cocoa. American Journal of Clinical Nutrition, 76, 798-804.

Horsley, E. T., Burkitt, M. J., Jones, C. M., Patterson, R. A., Harris, L. K., Moss, N. J., et al. (2007). Mechanism of the antioxidant to pro-oxidant switch in the behavior of dehydroascorbate during LDL oxidation by copper(II) ions. Archives of Biochemistry and Biophysics, 465, 303-314.

Huber, A., Stuchbury, G., Bürkle, A., Burnell, J., \& Münch, G. (2006). Neuroprotective therapies for Alzheimer's disease. Current Pharmaceutical Design, 12, 705-717.

Jarjour, N. N., \& Calhoun, W. J. (1994). Enhanced production of oxygen radicals in asthma. The Journal of Laboratory and Clinical Medicine, 123, 131-136.

Jie, G., Lin, Z., Zhang, L., Lv, H., He, P., \& Zhao, B. (2006). Free radical scavenging effect of Pu-erh tea extracts and their protective effect on oxidative damage in human fibroblast cells. Journal of Agricultural and Food Chemistry, 54, 8058-8064.

Juan, M. E., Wenzel, U., Ruiz-Gutiérrez, V., Daniel, H., \& Planas, J. M. (2006). Olive fruit extracts inhibit proliferation and induce apoptosis in HT-29 human colon cancer cells. Journal of Nutrition, 136, 2553-2557.

Kaplan, M., Mutlu, E. A., Benson, M., Fields, J. Z., Banan, A., \& Keshavarzian, A. (2007). Use of herbal preparations in the treatment of oxidant-mediated inflammatory disorders. Complementary Therapies in Medicine, 15, 207-216.

Kattenberg, H. R., \& Willemsen, J. H. A. (2003). The manufacture of cocoa polyphenols as healthy supplements in food products. IFIS Journal. Food Science - Central 3. <http://www.foodsciencecentral.com/library.html\#ifis/ 12553>.

Kennetta, E. C., \& Davies, M. J. (2007). Degradation of matrix glycosaminoglycans by peroxynitrite/peroxynitrous acid: Evidence for a hydroxyl-radical-like mechanism. Free Radical in Biology and Medicine, 42, 1278-1289.
Keshavarzian, A., Sedghi, S., Kanofsky, J., List, T., Robinson, C., Ibrahim, C., et al. (1992). Excessive production of reactive oxygen metabolites by inflamed colon: Analysis by chemiluminescence probe. Gastroenterology, 103, 177-185.

Kim, H., \& Keeney, P. G. (1984). (-)-Epicatechin content in fermented and unfermented cocoa beans. Journal of Food Sciences, 49, 1090-1092.

Koppenol, W. H., Kissner, R., \& Beckman, J. S. (1996). Syntheses of peroxynitrite: To go with the flow or on solid grounds? Methods in Enzymology, 269, 296-302.

Lamuela-Raventós, R. M., Romero-Pérez, A. I., Andrés-Lacueva, C., \& Tornero, A (2005). Review: Health effects of cocoa flavonoids. Food Science and Technology International, 11, 159-176.

Lee, K. W., Kim, Y. J., Lee, H. J., \& Lee, C. Y. (2003). Cocoa has more phenolic phytochemicals and a higher antioxidant capacity than teas and red wine. Journal of Agricultural and Food Chemistry, 51, 7292-7295.

Liu, F., \& Ng, T. B. (2000). Antioxidative and free radical scavenging activities of selected medicinal herbs. Life Sciences, 66, 725-735.

Lopes, G. K. B., Schulman, H. M., \& Hermes-Lima, M. (1994). Polyphenol tannic acid inhibits hydroxyl radical formation from Fenton reaction by complexing ferrous ions. Biochimica and Biophysica Acta, 1472, 142-152.

Montesinos, M. C., Úbeda, A., Terencio, M. C., Payá, M., \& Alcaraz, M. J. (1995). Antioxidant profile of mono- and dihydroxylated flavone derivatives in free radical generating systems. Zeitschrift für Naturforschung, 50c, 552-560.

Mosmann, T. (1983). Rapid colorimetric assay for cellular growth and survival: Application to proliferation and cytotoxicity assays. Journal of Immunological Methods, 65, 55-63.

Motohashi, N., Kawase, M., Kurihara, T., Shirataki, Y., Kamata, K., Nakashima, H., et al. (1999). Relationship between radical intensity and biological activity of cacao husks extracts. Anticancer Research, 19, 1125-1130.

Ng, T. B., Liu, F., \& Wang, Z. T. (2000). Antioxidative activity of natural products from plants. Life Sciences, 66, 709-723.

Odeh, M. (1997). New insights into the pathogenesis and treatment of rheumatoid arthritis. Clinical Immunology and Immunopathology, 83, 103-116.

Pannala, A. S., Chan, T. S., O'Brien, J., \& Rice-Evans, C. (2001). Flanonoid B-ring chemistry and antioxidant activity: Fast reaction kinetics. Biochemical and Biophysical Research Communications, 282, 1161-1168.

Pasamar, M. A., Ibarra, A., Cienfuegos-Jovellanos, E., \& Laghi, S. (2006). Proceso de obtención de extractos de cacao con elevado contenido de polifenoles. Patent Cooperation Treaty (PCT) PCT/ES 2006 000294, Natraceutical Industrial, Spain.

Pitchumoni, S. S., \& Doraiswamy, P. M. (1998). Current status of antioxidant therapy for Alzheimer's disease. Journal of the American Geriatrics Society, 46 $1566-1572$.

Rein, D., Paglieroni, T. G., Wun, T., Pearson, D. A., Schmitz, H. H., Gosselin, R., et al (2000). Cocoa inhibits platelet activation and function. American Journal of Clinical Nutrition, 72, 30-35.

Rein, D., Lotito, S., Holt, R. R., Keen, C. L., Schmitz, H. H., \& Fraga, C. G. (2000) Epicatechin in human plasma: In vivo determination and effect of chocolate consumption on plasma oxidation status. Journal of Nutrition, 130 2109S-21014S.

Ren, W., Qiao, Z., Wang, H., Zhu, L., \& Zhang, L. (2003). Flavonoids: Promising anticancer agents. Medical Research Reviews, 23, 519-534.

Rios, L. Y., Bennet, R. N., Lazarus, S. A., Rémésy, C., Scalbert, A., \& Williamson, G. (2002). Cocoa procyanidins are stable during gastric transit in humans. American Journal of Clinical Nutrition, 76, 1106-1110.

Ruch, R. J., Cheng, S. J., \& Klaunig, J. E. (1989). Prevention of cytotoxicity and inhibition of intercellular communication by antioxidant catechins isolated from Chinese green tea. Carcinogenesis, 6, 1003-1008.

Sanbongi, C., Osakabe, N., Natsume, M., Takizawa, T., Gomi, S., \& Osawa, T. (1998) Antioxidative polyphenols isolated from Theobroma cacao. Journal of Agricultural and Food Chemistry, 46, 454-457.

Schlesier, K., Harwat, M., Bohm, V., \& Bitsch, R. (2002). Assessment of antioxidant activity by using different in vitro methods. Free Radical Research, 36, 177-187.

Schinella, G. R., Troiani, G., Dávila, V., de Buschiazzo, P. M., \& Tournier, H. A. (2000) Antioxidant effects of an aqueous extract of Ilex paraguariensis. Biochemical and Biophysical Research Communication, 269, 357-360.

Schinella, G. R., Tournier, H. A., Máñez, S., de Buschiazzo, P. M., Recio, M. C., \& Ríos, J. L. (2007). Tiliroside and gnaphaliin inhibit human low density lipoprotein oxidation. Fitoterapia, 78, 1-6.

Serafini, M., Bugianesi, R., Maiani, G., Valtuena, S., De Santis, S., \& Crozier, A. (2003) Plasma antioxidants from chocolate. Nature, 424, 1013.

Sheweita, S. A., Tilmisany, A. M., \& Al-Sawaf, H. (2005). Mechanisms of male infertility: Role of antioxidants. Current Drug Metabolism, 6, 495-501.

Sies, H., Schewe, T., Heiss, C., \& Kelm, M. (2005). Cocoa polyphenols and inflammatory meditors. American Journal of Clinical Nutrition, 81, S304-S312.

Singleton, V. L., \& Rossi, J. A. (1965). Colorimetric of total phenolics with phosphomolybdic-phosphotungstic acid reagents. American Journal of Enology and Viticulture, 16, 144-158.

Surh, Y. (1999). Molecular mechanisms of chemopreventive effects of selected dietary and medicinal phenolic substances. Mutation Research, 428 305-327.

Taubert, D., Roesen, R., Lehmann, C., Jung, N., \& Schömig, E. (2007). Effects of low habitual cocoa intake on blood pressure and bioactive nitric oxide. A randomize control trial. The Journal of the American Medical Association, 298, 49-60.

Tomás-Barberán, F. A., Cienfuegos-Jovellanos, E., Marín, A., Muguerza, B., GilIzquierdo, A., Cerdá, B., et al. (2007). A new process to develop a cocoa powder with higher flavonoid monomer content and enhanced bioavailability in healthy humans. Journal of Agricultural and Food Chemistry, 55, 3926-3935. 
Victor, V. M., Rocha, M., Esplugues, J. V., \& De la Fuente, M. (2005). Role of free radicals in sepsis: Antioxidant therapy. Current Pharmaceutical Design, 11, 3141-3158.

Wang, J. Y., Wen, L. L., Huang, Y. N., Chen, Y. T., \& Ku, M. C. (2006). Dual effects of antioxidants in neurodegeneration: Direct neuroprotection against oxidative stress and indirect protection via suppression of glia-mediated inflammation. Current Pharmaceutical Design, 12, 3521-3533.

Wang-Polagruto, J. F., Villablanca, A. C., Polagruto, J. A., Lee, L., Holt, R. R., Schrader H. R., et al. (2006). Chronic consumption of flavanol-rich cocoa improves endothelial function and decreases vascular cell adhesion molecule in hypercholesterolemic postmenopausal women. Journal of Cardiovascular Pharmacology, 47, S177-S186.

Waterhouse, A. L., Shirley, J. R., \& Donovan, J. L. (1996). Antioxidants in chocolate. The Lancet, 348, 834.
Weiss, S. J., Klein, R., Slivka, A., \& Wei, M. (1982). Chlorination of taurine by human neutrophils. Evidence for hypochlorous acid generation. Journal of Clinical Investigation, 70, 598-607.

Witztum, J. L., \& Steinberg, D. (1991). Role of oxidized low density lipoprotein in atherogenesis. Journal of Clinical Investigation, 88, 1785-1792.

Wollgast, J., \& Anklam, E. (2000). Polyphenols in chocolate: Is there a contribution to human health? Food Research International, 33, 449-459.

Yasui, K., \& Baba, A. (2006). Therapeutic potential of superoxide dismutase (SOD) for resolution of inflammation. Inflammation Research, 55, 359-363.

Yen, G. C., Duh, P. D., \& Chuang, D. Y. (2000). Antioxidant activity of anthraquinones and anthorne. Food Chemistry, 70, 437-441. 